www.jmscr.igmpublication.org Impact Factor 5.244

Index Copernicus Value: 83.27 ISSN (e)-2347-176x ISSN (p) 2455-0450 crossref DOI: _https://dx.doi.org/10.18535/jmscr/v4i11.34

\title{
A Study of Incidence, Clinical Features, Risk Factor Profile and Prognosis of Atrial Fibrillation in Hospitalised Elderly Patients
}

\author{
Authors \\ Dr R. Santha Prabu ${ }^{*}$, Dr N. Chidambaram ${ }^{2}$, Dr S. Periyasamy ${ }^{3}$, Dr K. Haynes Raja ${ }^{4}$ \\ ${ }^{1 *}$ Post Graduate, Department of General Medicine, Rajah Muthiah Medical College and Hospital, \\ Annamalai University, Annamalai Nagar - 608002 \\ ${ }^{2}$ Professor and Dean, Department of General Medicine, Rajah Muthiah Medical College and Hospital, \\ Annamalai University, Annamalai Nagar - 608002 \\ ${ }^{3}$ Associate Professor, Department of General Medicine, Rajah Muthiah Medical College and Hospital, \\ Annamalai University, Annamalai Nagar - 608002 \\ ${ }^{4}$ Post Graduate, Department of General Medicine, Rajah Muthiah Medical College and Hospital, Annamalai \\ University, Annamalai Nagar - 608002
}

\begin{abstract}
Atrial fibrillation is the commonest sustained disorder of cardiac rhythm. Epidemiological studies shows that atrial fibrillation is fairly uncommon in people aged under 50 years but is found in $0.5 \%$ of people around 60 years and increases to $8.8 \%$ at around 80 yrs. This study is taken up to understand the Incidence, Clinical Features, Risk Factor profile and prognosis of Atrial Fibrillation in Hospitalised Elderly patients.

METHODS: This is a descriptive study conducted among the patients with various types of cardiac dysarrhythmia admitted in RMMCH. 100 patients were evaluated as per the history, general physical examination, systemic examination. Blood sugar, fasting lipid profile, serum electrolytes, fasting thyroid profile, 12 lead ECG and 2D Transthoracic echocardiography.

RESULTS: In our study, Atrial Fibrillation was the most common dysarrhythmia found in 19 patients. 16 patients (84\%) belonged to 60 - 70 years age group. There were $8(42 \%)$ males and 11(58\%) females. Palpitation was the most common (100\%) and Limb weakness was the least common (10\%) clinical feature. Rheumatic Heart disease was found to be the most common risk factor seen in 9 (47\%) patients. Mitral Stenosis with Mitral Regurgitation was the most common valvular abnormality seen in the 5 (55\%) Rheumatic Heart Disease patients. Other important risk factors include Hypertension and Hyperthyroidism each accounting for $4(21 \%)$ patients. Among the 19 patients of Atrial Fibrillation, rate control was achieved in $16(85 \%)$ patients and full recovery in the rest.

CONCLUSION: In our study, most patients belonged to 60 - 70 yrs age group with female predominance. Palpitation was found to be the most common clinical feature. Rheumatic Heart disease was found to be the most common risk factor in our study and Mitral Stenosis with Mitral Regurgitation was the most common valvular abnormality among them. Among the Atrial Fibrillation patients, rate control was achieved in 16 patients and full recovery in the rest suggesting a good prognosis. Alcohol consumption induced atrial fibrillation and Hyperthyroidism were found to be the fully reversible causes of Atrial Fibrillation.
\end{abstract}

Key Words: Atrial Fibrillation, Rheumatic Heart Disease, Hyperthyroidism. 


\section{INTRODUCTION}

Atrial fibrillation (AF) poses a major global public health challenge because it is increasing in prevalence and is associated with an increased risk of stroke, dementia, heart failure, and death ${ }^{(1,2)}$. At 40 years of age, the remaining lifetime risk for developing $\mathrm{AF}$ is $\approx 1$ in 4 for both white men and women, and it remains as high at older ages because of the steeply increasing risk for $\mathrm{AF}$ with advancing age (the comparable lifetime risk in men and women is due to the greater longevity of women). ${ }^{(3,4)}$ Abundant studies are available about the Incidence, Clinical Features, Risk Factor profile and prognosis of Atrial Fibrillation in Hospitalised Elderly patients in western population. This study is taken up to understand the Incidence, Clinical Features, Risk Factor profile and prognosis of Atrial Fibrillation in Hospitalised Elderly patients in rural population.

\section{RESEARCH METHODOLOGY}

The study was conducted among the patients admitted with dysarrhythmias in CCU and ICU of Rajah Muthiah Medical College Hospital.

\section{METHODS}

A minimum of 100 patients with ECG changes of cardiac arrhythmias were taken for the study. Following investigations were done after detailed clinical evaluation.

\section{CBC with ESR}

2. FBS, PPBS, RBS

3. Fasting Lipid Profile

4. BUN, Sr. Creatinine

5. Sr. Electrolytes

6. Fasting Thyroid Profile

7. Cardiac enzymes
8. Chest $\mathrm{X}$ ray

9. All patients were subjected to 12 lead ECG and detailed Trans-thoracic Echocardiography (ECHO) and Doppler evaluation using PHILIPS IE33 High Performance Echocardiography machine.

\section{Study Type:}

Descriptive Cross Sectional Study

\section{Inclusion Criteria:}

Both sexes of age above 60 yrs with ECG changes of cardiac arrhythmia were taken.

\section{OBSERVATION AND RESULTS}

- Most patients (84\%) belonged to the $60-$ 70 yrs age group

- The total number of male patients were 8 (42\%) and female patients were 11 (58\%)

- Palpitation was the most common (100\%) and Limb weakness was the least common (10\%) clinical feature

- Rheumatic Heart disease was found to be the most common risk factor seen in 9 (47\%) patients.

- Hypertension and Hyperthyroidism were found to be the other most important risk factors each accounting for $4(21 \%)$ patients.

- Mitral Stenosis with Mitral Regurgitation was the most common valvular abnormality seen in $5(55 \%)$ Rheumatic Heart Disease patients.

- Rate Control was achieved in $16(85 \%)$ patients

- Full recovery in $3(15 \%)$ patients with hyperthyroidism and Alcohol consumption induced atrial fibrillation.

TABLE 1. Age Wise Distribution

\begin{tabular}{|l|l|c|c|}
\hline S.No. & Age group & No. of cases & Percentage \\
\hline 1. & $60-65$ years & 8 & 42 \\
\hline 2. & $66-70$ years & 8 & 42 \\
\hline 3. & $71-75$ years & 1 & 5 \\
\hline 4. & $76-80$ years & 1 & 5 \\
\hline 5. & $>80$ years & 1 & 5 \\
\hline
\end{tabular}


TABLE 2. Gender Wise Distribution

\begin{tabular}{|l|l|c|c|}
\hline S.No. & Gender & No. of cases & Percentage \\
\hline 1. & Males & 8 & 42 \\
\hline 2. & Females & 11 & 58 \\
\hline
\end{tabular}

TABLE 3. Clinical Features

\begin{tabular}{|l|l|c|c|}
\hline S.No. & Clinical Features & No. of cases & Percentage \\
\hline 1. & Palpitation & 19 & 100 \\
\hline 2. & Dyspnea & 16 & 84 \\
\hline 3. & Giddiness & 13 & 68 \\
\hline 4. & Chest Pain & 13 & 68 \\
\hline 5. & Fatiguability & 12 & 63 \\
\hline 6. & Orthopnea & 11 & 58 \\
\hline 7. & Leg Swelling & 7 & 37 \\
\hline 8. & Decreased urine output & 4 & 21 \\
\hline 9. & Paroxysmal Nocturnal Dyspnea & 3 & 15 \\
\hline 10. & Head Ache & 3 & 15 \\
\hline 11. & Limb Weakness & 2 & 10 \\
\hline
\end{tabular}

TABLE 4. Risk Factors

\begin{tabular}{|l|l|c|c|}
\hline S.No. & Risk Factors & No. of cases & Percentage \\
\hline 1. & Rheumatic Heart disease & 9 & 47 \\
\hline 2. & Hypertension & 4 & 21 \\
\hline 3. & Hyperthyroidism & 4 & 21 \\
\hline 4. & Coronary Artery Disease & 1 & 5 \\
\hline 5. & Alcohol Consumption & 1 & 5 \\
\hline
\end{tabular}

TABLE 5. Valvular Lesions In Rheumatic Heart Disease Patients With Atrial Fibrillation

\begin{tabular}{|l|l|c|c|}
\hline S.No. & Valvular Lesions & No. of cases & Percentage \\
\hline 1. & MS with MR & 5 & 55 \\
\hline 2. & MS & 2 & 22 \\
\hline 3. & MS MR with AR & 1 & 11 \\
\hline 4. & MS MR with AS & 1 & 11 \\
\hline
\end{tabular}

TABLE 6. Prognosis

\begin{tabular}{|l|l|c|c|}
\hline S.No. & Prognosis & No. of Cases & Percentage \\
\hline 1. & Recovered & 3 & 15 \\
\hline 2. & Controlled & 16 & 85 \\
\hline
\end{tabular}

\section{RESULTS}

In our study, Atrial Fibrillation was the most common dysarrhythmia found in 19 patients. Majority of patients $16(84 \%)$ belonged to $60-70$ years age group. There were $8(42 \%)$ males and $11(58 \%)$ females. Palpitation was the most common(100\%) and Limb weakness was the least common(10\%) clinical feature. Rheumatic Heart disease was found to be the most common risk factor seen in $9(47 \%)$ patients. Mitral Stenosis with Mitral Regurgitation was the most common valvular abnormality seen among 5 (55\%) 
Rheumatic Heart Disease patients. Other important risk factors include Hypertension and Hyperthyroidism each accounting for 4 (21\%) patients. Among the 19 patients of Atrial Fibrillation, rate control was achieved in $16(85 \%)$ patients and full recovery in the rest.

\section{DISCUSSION}

Curt D Furberg et al and Grant V. Chow et al showed that Normal aging is associated with a higher incidence of many cardiac arrhythmias including Atrial Fibrillation ${ }^{(5,6)}$. A study by Michiel Rienstra, MD et al showed that the most common arrhythmia encountered in clinical practice was atrial fibrillation $^{(7)}$. In our study, the most common arrhythmia encountered was Atrial fibrillation seen in 19 patients (8 males and 11 females) out of the 100 patients with dysarrhythmias. Michiel Rienstra, MD et al, showed that the most common symptom is Palpitation $^{(7)}$. In our study, Palpitation was the most common (100\%) and Limb weakness was the least common (10\%) clinical feature. Rajdatt Deore et al study showed that the most common cause of nonvalvular Atrial Fibrillation is Hypertension whereas in India valvular Atrial fibrillation due to Rheumatic heart disease predominates $^{(8)}$. In our study, Rheumatic Heart disease was found to be the most common risk factor seen in 9 (47\%) patients. Mitral Stenosis with Mitral Regurgitation was the most common valvular abnormality seen among 5 (55\%) Rheumatic Heart Disease patients. A study done by K-H Yiuet al showed that in patients with hypertension, alteration of cardiac haemodynamic, structural and electrophysiological properties imposed by hypertension and LVH can contribute to the development of Atrial Fibrillation, ventricular arrhythmia and $\mathrm{SCD}^{(9)}$. Hwang JK et al showed that the most common risk factor implicated in Atrial fibrillation is Hypertension. In the study done by Agner $\mathrm{T}$ et al, $25 \%$ of hyperthyroid patients older than 60 years had atrial fibrillation compared to $5 \%$ in patients less than 60 years of age ${ }^{(10)}$. In our study, Other important risk factors for development of Atrial fibrillation include Hypertension and Hyperthyroidism each accounting for 4 (21\%) patients. A study by Bartalena $\mathrm{L}$ et al showed that Atrial Fibrillation induced by Thyrotoxicosis is completely reversible in upto $50 \%$ of the patients $^{(11)}$. Among the 19 patients of Atrial Fibrillation in our study, rate control was achieved in $16(85 \%)$ patients and full recovery in the rest. In our study, Atrial fibrillation was fully reverted to normal sinus rhythm in 2 patients $(50 \%)$ with Hyperthyroidism.

\section{CONCLUSION}

In our study, most patients belonged to $60-70$ years age group with female predominance. Palpitation was found to be the most common clinical feature. Rheumatic Heart disease was found to be the most common risk factor in our study and Mitral Stenosis with Mitral Regurgitation was the most common valvular abnormality. Among the 19 patients of Atrial Fibrillation, rate control was achieved in 16 patients and full recovery in the rest suggesting a good prognosis. Alcohol consumption induced atrial fibrillation and Hyperthyroidism were found to be the fully reversible causes of Atrial Fibrillation.

\section{REFERENCES}

1. Benjamin EJ, Chen PS, Bild DE et al. Prevention of atrial fibrillation: report from a National Heart, Lung, and Blood Institute Work shop. Circulation. 2009; 119:606-618.

2. Schnabel RB, Sullivan LM et al,. Development of a risk score for atrial fibrillation (Framingham Heart Study): a community-based cohort study. Lancet. 2009;373:739-745

3. Lloyd-Jones DM, Wang TJ, Leip EP, Larson MG, Levy D, Vasan RS, D'Agostino RB, Massaro JM, Beiser A, Wolf PA, Benjamin EJ. Lifetime risk for development of atrial fibrillation: the 
Framingham Heart Study. Circulation. 2004; 110: 1042-1046.

4. Heeringa J, Van Der Kuip DA, Hofman A, Kors JA, van Herpen G, Stricker BH, Stijnen T, Lip GY, Witteman JC. Prevalence, incidence and lifetime risk of atrial fibrillation: the Rotterdam Study. Eur Heart J.2006; 27: 949-953.

5. Curt D Furberg, Bruce M. Psaty, Teri Manolio, Pentti M. Rautaharju; Prevalence of atrial fibrillation in elderly subjects (the Cardiovascular Health Study) The American Journal of Cardiology 74 (3):236-41. September 1994.

6. Epidemiology of Arrhythmias and Conduction Disorders in Older Adults Grant V. Chow, M.D., Joseph E. Marine, M.D., and Jerome L. Fleg, M.D. Clin Geriatric Med. 2012 Nov; 28(4): 539-553.

7. Symptoms and Functional Status of Patients With Atrial Fibrillation State of the Art and Future Research Opportunities Michiel Rienstra, MD, PhD; Steven A. Lubitz, MD, MPH Circulation. 2012;125:2933-2943

8. Rajdatt Deore, MD; AmitVora, MD, DM, Epidemiology and risk factor of atrial fibrillation in India. J. Preventive Cardiology Vol.3, No. 3, 2014

9. Hypertension and cardiac arrhythmia: a review of the epidemiology, pathophysiology and clinical implications. Yiu KH, Tse HF. J Hum Hypertens. 2008 Jun;22(6):380-8

10. A reevaluation of atrial fibrillation in thyrotoxicosis.Agner T, Almdal T, Thorsteinsson B, Agner E Dan Med Bull. 1984 Apr; 31(2):157-9.

11. Bartalena L, Hennemann G. Graves' Disease: Complications. [Updated 2014 Feb 12]. In: De Groot LJ, Chrousos G, Dungan K, et al., editors. Endotext. South Dartmouth (MA): 